\title{
The Cardio-Vascular and Metabolic Treatments in Canada: Assessment of Real-Life Therapeutic Value Registry (CV-CARE): Registry Description and Baseline Patient Demographics
}

\author{
Goldenberg Ronald ${ }^{1}$, Cheng Willoon ${ }^{2}$, Bell Alan ${ }^{3}$, Burrows Melonie $^{4}$, Blavignac Jessica 4 , Paron Emilia 4 , \\ Nadège Fils-Aimé (4* $^{*}$ and Barakat Maxime ${ }^{4}$
}

${ }^{1}$ LMC Diabetes and Endocrinology, Ontario, Canada

${ }^{2}$ Tillsonburg Medical Centre, Ontario, Canada

${ }^{3}$ University of Toronto, Ontario Canada

${ }^{4}$ Bausch Health, Quebec, Canada

*Corresponding author: Dr. Melonie Burrows, Bausch Health, 2150 Boulevard St-Elzéar West, Laval, Québec, H7L 4A8, Canada

\begin{abstract}
Background: Bausch Health Canada cardiovascular and metabolic treatment portfolio has been shown to be safe and effective in clinical trials. However, in clinical trials, data is collected in selective populations under ideal conditions, making inference to the real-world problematic. Well executed patient registries are required to provide evidence of the benefits of therapeutic agents under routine, real world conditions. The 'Cardio-Vascular and metabolic treatments in Canada: Assessment of REal-life therapeutic value' registry (CV-CARE) is the first attempt to describe the real-world effectiveness of Bausch Health Canada cardiovascular and metabolic treatments. Our objectives are to introduce CVCARE and describe baseline patient, disease and treatment characteristics.

Methods: CV-CARE was a Canadian, multi-center, community-based, prospective cohort registry in patients initiating one or more of Bausch Health Canada cardiovascular and metabolic treatments; metformin extended-release for type 2 diabetes mellitus (T2DM), colesevelam for hypercholesterolemia ( $\mathrm{HCh})$, and/or azilsartan (AZI), azilsartan/chlorthalidone $(\mathrm{AZI} / \mathrm{CHL})$, or diltiazem extended-release $(T X C)$ for hypertension (HTN). CV-CARE ran in 300 specialist and GP centers between 2015-2018. Treating physicians used standardized case report forms, patient interviews and chart reviews for data collection. Descriptive statistics were used to describe baseline patient, disease and treatment characteristics.
\end{abstract}

Results: The registry enrolled 6960 patients; 4194 patients make up this baseline population. $56.3 \%$ were male, $50 \%$ were Caucasian. Mean age was 59.6 years. $23.7 \%$ were treated for T2DM, 39\% for HCh, and $49.1 \%$ for HTN. Mean disease duration was 4.9 years (T2DM), 4.9 years $(\mathrm{HCh})$ and 6.7 years (HTN). Mean body mass index was $30 \mathrm{~kg} \cdot \mathrm{m}^{-2}$. $11 \%$ were current smokers; $80 \%$ previous smokers.

Conclusion: This paper describes, for the first time, the CVCARE registry and characterizes baseline demographics and disease/treatment characteristics of Canadian patients on a Bausch Health Canada cardiovascular and metabolic treatment. The CV-CARE registry will be utilized to assess the real-world effectiveness of Bausch Health Canada treatments, and to investigate regional variability of disease management across Canadian provinces.

\section{Keywords}

CV-CARE registry, Hypercholesterolemia, Hypertension, Routine-care, Type 2 diabetes mellitus
Abbreviations
A1C: Glycated hemoglobin; A: Albumin creatinine ratio; B: Body mass index; DBP: Diastolic blood pressure; Egfr: Esti- mated glomerular filtration rate; FPG: Fasting plasma glu- cose; HDL-C: High density lipoprotein cholesterol; LDL-C: Low-density lipoprotein-cholesterol; SBP: Systolic blood pressure; TC: Total cholesterol; TG: Triglycerides

Citation: Ronald G, Willoon C, Alan B, Melonie B, Jessica B, et al. (2020) The Cardio-Vascular and Metabolic Treatments in Canada: Assessment of Real-Life Therapeutic Value Registry (CV-CARE): Registry Description and Baseline Patient Demographics. J Hypertens Manag 6:053. doi.org/10.23937/24743690/1510053

Accepted: December 10, 2020: Published: December 12, 2020

Copyright: (c) 2020 Ronald G, et al. This is an open-access article distributed under the terms of the Creative Commons Attribution License, which permits unrestricted use, distribution, and reproduction in any medium, provided the original author and source are credited. 


\section{Introduction}

Cardiometabolic disease is a collection of metabolic dysfunctions categorized by overweight or obesity, insulin resistance/dysglycemia, dyslipidemia and hypertension [1,2]. In Canada, 2.4 million people have been diagnosed with diabetes, $90 \%$ of which have type 2 diabetes mellitus (T2DM) [3]. Glycated hemoglobin (A1C) reductions are linked to reduced risk of diabetic complications [4]. However, only $50 \%$ of patients with T2DM in Canada meet the A1C target of $\leq 7.0 \%$, only $57 \%$ reach the low-density lipoprotein-cholesterol (LDL-C) target of $\leq 2.0 \mathrm{mmol} / \mathrm{L}$, only $36 \%$ reach the systolic blood pressure $(\mathrm{SBP})<130 \mathrm{mmHg}$, and only $13 \%$ reach the triple target [5]. Metformin immediate-release (IR) is a traditional first-line antihyperglycemic agent but up to $25 \%$ of metformin IR patients develop gastrointestinal (GI) side effects leading to cessation of use [6]. Metformin extended-release (MetER) preparations may be associated with fewer GI side effects compared to metformin IR [7]. A once daily MetER was developed for better adherence, with efficacy and safety results similar to metformin IR [8]. It was approved for use by Health Canada in 2011 [9].

Hypercholesterolemia ( $\mathrm{HCh})$ is directly associated with an increased risk of cardiovascular disease [10-12]. Data from clinical trials on more than 170,000 patients evaluating lipid-lowering medications has shown that lowering LDL-C is associated with significant reductions in cardiovascular morbidity and mortality [13]. As a result, the Canadian Cardiovascular Society recommends a primary target of lipid-lowering therapy (LLT) of LDL-C to $<2.0 \mathrm{mmol} / \mathrm{L}$ and/or by $50 \%$ [14]. In high risk patients, an LDL-C target of $1.8 \mathrm{mmol} / \mathrm{L}$ should be considered. This reduction considerably lowers the risk of cardiovascular disease, mortality, nonfatal myocardial infarction, and recurrent cardiovascular disease events $[15,16]$. Additional reductions in LDL-C to $1.4 \mathrm{mmol} / \mathrm{L}$ and even below $1 \mathrm{mmol} / \mathrm{L}$ in very high-risk patients are associated with further cardiovascular event reduction $[17,18]$ and are recommended by the 2019 European Society of Cardiology lipid guidelines [19]. Many patients on statins, the standard of care for hypercholesterolemia, do achieve therapeutic goals [20]. For those not achieving target, the Canadian Cardiovascular Society recommends add-on therapy (ezetimibe, bile acid sequestrants, PCSK9 inhibitors) for high-risk patients [14]. The bile acid sequestrant Colesevelam (C) hydrochloride (HCL) was approved by Health Canada in 2011 for the reduction of blood cholesterol in patients with hypercholesterolemia based on studies that showed greater reductions in LDL-C compared to placebo at all doses studied [21].

Elevated blood pressure is the leading risk factor for death and disability-adjusted life-years lost [22]. The Canadian prevalence of hypertension (HTN) is estimated at $20 \%$ and is forecasted to increase [23]. Despite the availability of a variety of anti-hypertensive treatments in Canada, 34\% of treated patients are still not at target [24]. In 2014, azilsartan medoxomil (AZI) [25] an angiotensin receptor blocker (ARB), was launched in Canada for the treatment of mild to moderate essential HTN $[26,27]$. In 2016, Health Canada also approved a fixed dose combination of azilsartan medoxomil with chlorthalidone (AZI/CHL) [25] for the treatment of severe HTN $[28,29]$. Both new treatments were shown to significantly decrease blood pressure compared to best in class standard of care $[27,28]$. Diltiazem extended-release (ER) [30], a calcium channel blocker (CCB) for the treatment of mild to moderate essential HTN, provides an additional medication choice with a novel delivery system proven to be effective in $24 \mathrm{hr}$ blood pressure control [31].

Metformin ER, C, AZI, AZI/CHL and Diltiazem are part of the bausch health canada (BHC) cardiovascular (CV) and metabolic (MET) portfolio. Although all drugs have been shown to be safe and effective in clinical trials, such data is collected in selective populations under ideal conditions, making inference to the real-world problematic [32]. Post approval clinical epidemiological studies (PACES), including post marketing prospective observational studies and patient registries, are the only source of information that allows assessment of real-world effectiveness [32]. The CV-CARE registry is the first systematic attempt to assess patients being treated with BHC CV/MET treatments in Canada in routine clinical care settings.

\section{Methods}

\section{Registry objectives}

The primary objective of the CV-CARE registry was to describe the real-world effectiveness of CV/MET treatments in BHC portfolio (MetER for T2DM, C for HCh and $\mathrm{AZI}, \mathrm{AZI} / \mathrm{CHL}$ or TXC for HTN), in patients with $\mathrm{CV} /$ MET diseases followed under Canadian routine clinical practice. Secondary objectives of CV-CARE were to describe the profile of patients treated with the registry drugs and to investigate the regional variations across Canadian provinces. This report describes the CV-CARE registry for the first time and the baseline profile of patients.

\section{Registry design and population}

The registry was a multi-site, Canadian, community-based, prospective, non-interventional program. Three hundred sites across Canada were recruited. Patients were recruited by treating physicians or nurse practitioners at each site. There were no interventions in patient management and treatments used were those as per the standard of care at each site and the clinical judgement of the treating physician. All patients were followed for 24 months and underwent three visits; day 0 (baseline), month 12 ( \pm 6 months) and month 24 ( \pm 6 months). Study assessments and administration 
of a case report form (CRF) questionnaire took place during routine care at each site. The decision to treat patients with study medication(s) must have been reached prior to, and independent of, the patient being enrolled into the registry. The study was approved by independent, centralized research ethics committees and informed consents were obtained. An independent clinical research organization (JSS Medical Research) designed and executed the registry on behalf of the sponsor (Valeant Canada).

Between 2015-2018 consenting patients who had a diagnosis with any combination of T2DM, $\mathrm{HCh}$, and/or HTN and who were prescribed one or more of the study drugs as part of their routine clinical care, were entered in the registry. Patients were eligible for CV-CARE registry entry if they were treated with a study drug(s), were $\geq 18$ years of age, the treating physician had reached a decision to treat the patient with the studied drug(s) prior to, and independently of, soliciting the patient to participate in the study, and the patient or legal representative (when allowable by law) had provided written informed consent. Patients were excluded from the registry if they had any contraindications to the use of study drug(s) as specified in the Canadian Product Monographs, and/or if the patient had any condition which, as per the judgment of the treating physician, prohibited them from participating in the study.

Table 1: Study assessments as per local practice.

\begin{tabular}{|l|c|c|c|}
\hline Assessment/Procedure & \multicolumn{2}{|c|}{ Visit } \\
\cline { 2 - 4 } & Baseline & $\mathbf{1 2}$ months & \\
\hline Inclusion/Exclusion criteria & $X$ & \\
\hline Informed consent & $X$ & \\
\hline Demographics & $X$ & $X^{\dagger}$ \\
\hline Date of diagnosis of treating condition(s) & $X$ & $X^{\ddagger}$ \\
\hline Medical history and Comorbidities & $X$ & $X^{\dagger}$ \\
\hline Anthropometric measurements & $X$ & $X$ \\
\hline Concomitant medication use for treating condition(s) & $X$ & $X^{\ddagger}$ \\
\hline Dose of studied drug(s) & $X$ & $X$ \\
\hline Disease parameters§ & $X$ & $X$ \\
\hline Adverse event assessment & $X$ & $X$ \\
\hline
\end{tabular}

†Only changes from previous visit were collected; ${ }^{\ddagger}$ Only weight and waist circumference; ${ }^{\S}$ Shown in panel 2 . Indication and modality of use was assessed only at baseline.

Table 2: Disease parameters as per local practice.

\begin{tabular}{|c|c|c|c|}
\hline \multirow[t]{2}{*}{ Assessment/ Procedure } & \multicolumn{3}{|c|}{ Visit } \\
\hline & $\begin{array}{l}\text { Metformin HCL, } \\
\text { Extended release }\end{array}$ & Colesevalam HCL & $\begin{array}{l}\text { Azilsartan Medoxomil } \\
\pm \text { Clorthalidone }\end{array}$ \\
\hline Indication§ & $x$ & $x$ & $x$ \\
\hline Modality of use $e^{\S}$ & & $\mathrm{X}$ & \\
\hline $\begin{array}{ll}\text { Lipid profile } \\
\begin{array}{ll}\text { - } & \text { LDL-C } \\
\text { - } & \text { Total cholesterol } \\
\text { - } & \text { HDL-C } \\
\text { - } & \text { Nono-B } \\
\text { - } & \text { Triglycerides }\end{array}\end{array}$ & & $x$ & \\
\hline A1C & $x$ & $\mathrm{X}$ & \\
\hline Blood pressure (SBP/DBP) & & & $x$ \\
\hline Pulse & & & $x$ \\
\hline Albumin/Creatinine Ratio & $x$ & & $x$ \\
\hline eGFR & & & $x$ \\
\hline Serum Potassium & & & $x$ \\
\hline Fasting plasma glucose & $x$ & $\mathrm{X}$ & \\
\hline
\end{tabular}

§Indication and modality of use was assessed only at baseline. 


\section{Schedule and procedures}

All patients were treated and followed for 24 months. The scheduling of procedures is outlined in (Table 1 and Table 2).

Patient's demographics (date of birth, sex, smoking status $(\mathrm{Y} / \mathrm{N})$, \# cigarettes per day, previous smoking duration and pack years (pack years = \# cigarettes/day $\mathrm{x} \#$ years as a smoker) and race (Caucasian, Black, Asian, Hispanic and Other)) were collected via patient interviews. Height $(\mathrm{m})$, weight $(\mathrm{kg})$ and waist circumference (cms) were measured in the treating physician's office according to local standards. Date of disease diagnoses, medical history, including comorbid cardiovascular/ metabolic diseases were collected via patient interview and chart review.

Disease parameters were evaluated at baseline, month 12 and month 24. Blood and urine samples were collected and sent for laboratory testing as per local clinical practice. Pulse, SBP and diastolic blood pressure (DBP) were measured at the physicians' office following the 2013 canadian hypertension education program (CHEP) guidelines [33]. The average of the 2 measurements was used for the evaluation of blood pressure control. The 2013 clinical practice guidelines for the pharmacologic management of T2DM [34], the 2012 Canadian cardiovascular society guidelines for the diagnosis and treatment of dyslipidemia in adults [35], and the 2015 hypertension education program recommendations for blood pressure and treatment of hypertension [36] were used to diagnose T2DM, HCh and HTN respectively. Dose of study drugs were assessed at baseline and subsequent dose changes, along with associated reasons, were recorded at each follow up visit (month 12 and month 24). All concomitant medications used and any changes over time were documented, including dose, frequency and duration of treatment. All adverse events (AEs) and serious adverse events (SAEs), including major cardiac events (MACE) were reported to the sponsor pharmacovigilance department.

\section{Registry medication}

The decision to initiate treatment was solely the responsibility of the treating physician and the patient. As such, it was a non-randomised process. Given the observational nature of the registry, all treatments were accessed as per routine clinical practice in each region. More specifically, the sponsor, the study coordination centre or investigators did not supply or reimburse for any treatment use by the patients in the study. Patients were prescribed the medications by the treating physician and acquired medications through available insurance plans/government reimbursement or purchase with their own funds.

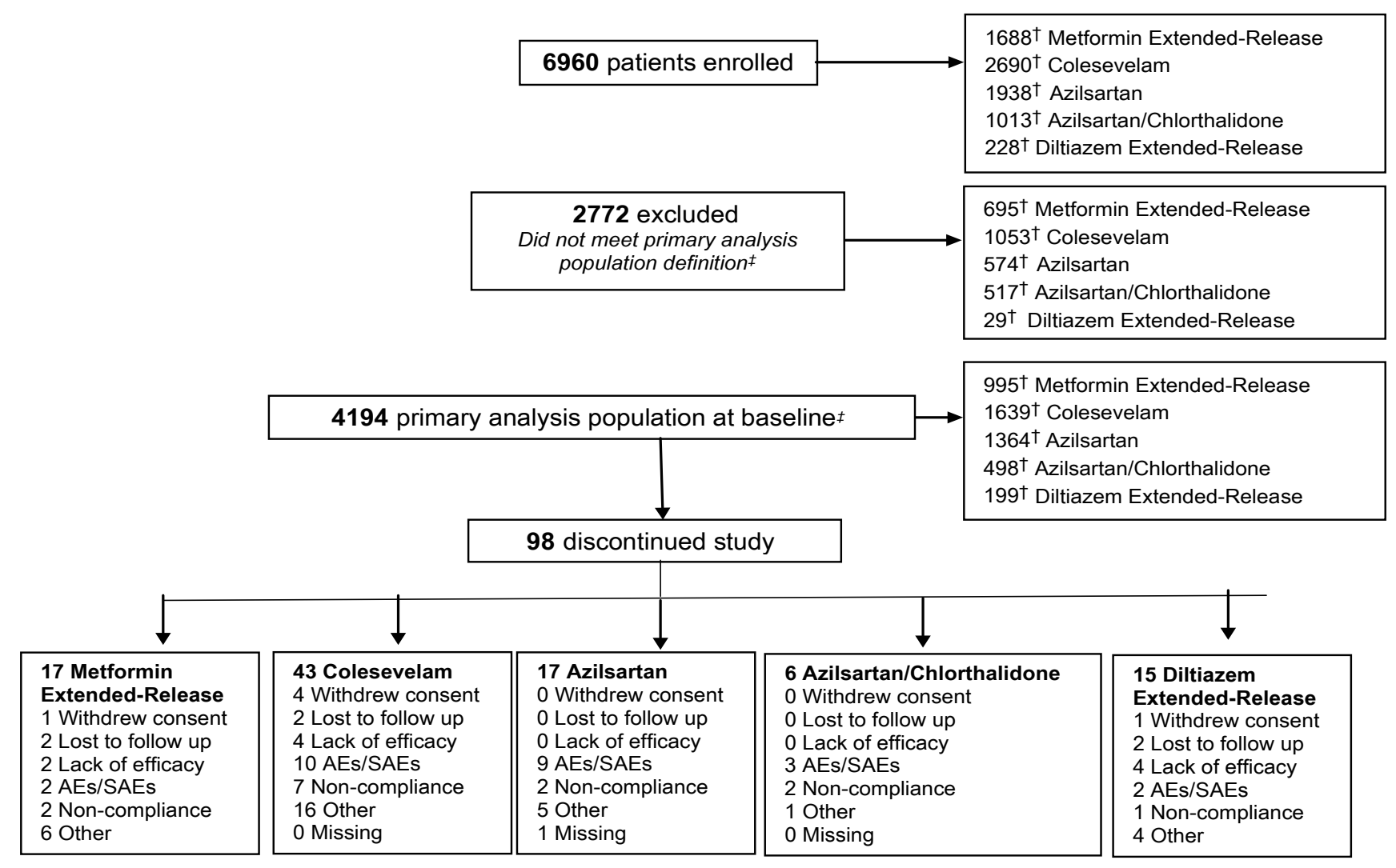

Figure 1: Flow of patients through the CV-CARE registry.

†Note that patients may have taken more than one study drug and therefore maybe represented in more than one study drug group; :Defined as all enrolled patients in the study who received at least one dose of study drugs, had at least one follow-up assessment visit and meet the selection criteria. 
As CV-CARE was a real world, observational study with the aim to collect data during routine, Canadian clinical care, all measurements defined in the protocol were requested. However, investigators were asked to conduct their clinical practice as they would in 'real life' and collect data as per their routine clinical care. As a result, data gaps were expected. To maintain the observational nature of the study, violations of inclusion and exclusion criteria did not necessarily result in discontinuation of the patients. Patients were maintained in the study if, in the opinion of their physician, treatment with the studied drug(s) continued to be indicated and was safe.

\section{Registry outcome measures and planned statis- tical analyses}

The primary outcome of the registry was to assess real-life effectiveness of MetER, C, AZI, AZI/CHL and Diltiazem. Specific disease primary outcomes were; 1 ) For patients with T2DM treated with MetER the absolute change in baseline $\mathrm{A} 1 \mathrm{C}$ and fasting plasma glucose at $12 \pm 6$ months, 2) For patients with $\mathrm{HCh}$, the percent change from baseline LDL-C at $12 \pm 6$ months, 3) For patients with HTN, the absolute change from baseline SBP at $12 \pm 6$ months. Secondary outcomes for the registry included the primary outcomes mentioned above at $24 \pm 6$ months and, in addition, the following; for patients with $\mathrm{HCh}$, the absolute change in total cholesterol, HDL-C, Apo-B, non-HDL-C, triglycerides, A1C and fasting plasma glucose at $12 \pm 6$ months and $24 \pm$ 6 months; for patients with HTN, the achievement of target BP (rate of responders) as per CHEP [36]; proportion of patients still on study drugs at 1 and 2 years; and safety and tolerability of study drugs assessed by SAEs, including MACE and treatment emergent AEs. Sample size determination was based on known clinically meaningful differences for our chosen primary outcome variables and a conservative estimate of expected changes over 12 months. Precision was assessed using $95 \%$ confidence intervals. A minimum of 1945 patients treated with MetER were required to obtain sufficient precision with respect to $A 1 C$ reduction; 2751 patients treated with $\mathrm{C}$ were required to obtain sufficient precision with respect to LDL-C reduction; 480/949 patients were required in order to obtain sufficient precision for changes in SBP and DBP with AZI respectively; and 1362 ( $\mathrm{AZI} / \mathrm{CHL}$ ) patients were required to obtain sufficient precision for changes in SBP. Assuming a $10 \%$ attrition rate by 12 months, a sample size of 8000 patients were deemed required.

\section{Statistical analyses for this descriptive study}

For this paper, we aimed to characterize the baseline demographics and disease/treatment characteristics of Canadian patients on a BHC CV/MET treatment. To that aim, descriptive statistics, including mean and standard deviation (SD) for continuous variables and counts and proportions for categorical variables, were used to describe the baseline patient profile and treatment. Two patient cohorts were defined for analysis - primary analysis population and safety population. The primary analysis population comprised all patients enrolled in the registry, who had received at least one dose of study drug, had a baseline visit and at least one follow up assessment visit, and met the selection criteria. The safety population were all those patients that received at least one dose of study drug. Given the observational nature of the study, all observations were included in the analyses and no data imputation for missing data took place. Histogram and formal tests for distribution found the baseline data to be normally distributed. All analyses were performed using SAS (version 9.4, SAS Institute Inc, Cary, NC) or SPSS (version 21.0, IBM Corp, Armonk, NY) software.

\section{Results}

In July 2018, following a thorough analysis of the datasets, it became clear that the primary outcomes had been met. As such, the decision was made to stop the registry early and study enrollment was closed in August 2018 with a final sample size of 6960 patients (Figure 1). Baseline characteristics, stratified by study drug, are shown in Table 3. Overall, 995 patients were prescribed MetER, 1639 C, 1364 AZI, 498 AZI/CHL, and 199 Diltiazem. Mean age was $59.6 \pm 11.7$ years, patients were predominately male $(56.3 \%)$, Caucasian $(50.0 \%)$, with $22 \%$ being overweight $\left(\mathrm{BMI}>27 \mathrm{mg} \cdot \mathrm{kg}^{2}\right)$ and $42 \%$ having obesity (> $\left.30 \mathrm{mg} \cdot \mathrm{kg}^{2}\right)$. Approximately $11 \%$ were current smokers, while $80 \%$ reported being previous smokers. The average disease duration was 4.9 years (T2DM), 4.9 years ( $\mathrm{HCh}$ ) and 6.7 years (HTN), with $23.7 \%$ being treated for T2DM, 39\% for HCh and $49.1 \%$ for HTN.

\section{Type 2 diabetes mellitus}

The diagnosis for initiating treatment with MetER was primarily T2DM (98.8\%). There were 3121 concomitant conditions in 1276 (75.5\%) of the MetER patients, with the majority of conditions classified as metabolic and nutritional disorders ( $57.9 \%)$, followed by vascular disorders (53.9\%), and cardiac disorders (5.7\%) (Figure 2A). There were 4413 concomitant medications being taken in 1427 (84.4\%) of the MetER patients, with antihyperglycemic agents (AHAs), LLT, and renin-angiotensin agents being the most common (Figure 3A). The most common total daily dose for MetER was $1000 \mathrm{mg}$ (Figure 4A). Metformin was most often taken as a switch from Metformin IR (60.6\%) versus being started as an initial treatment $(26.5 \%)$ or use with other AHAs (9.8\%). The major reason for switching from another treatment was tolerability (44.4\%) (Figure 5A).

\section{Hypercholesterolemia}

The diagnosis for initiating treatment with $\mathrm{C}$ was primarily HCh (95.9\%). There were 4911 concomitant con- 
Table 3: Patient demographics and disease characteristics by study drug ${ }^{\dagger}$.

\begin{tabular}{|c|c|c|c|c|c|}
\hline \multicolumn{6}{|l|}{ Study Drug } \\
\hline Characteristics & $\begin{array}{l}\text { Metformin ER } \\
\mathrm{n}=995\end{array}$ & $\begin{array}{l}\text { Colesevelam } \\
n=1639\end{array}$ & $\begin{array}{l}\text { Azilsartan } \\
n=1364\end{array}$ & $\begin{array}{l}\text { Azilsartan/ } \\
\text { Chlorthalidone } \\
n=498\end{array}$ & $\begin{array}{l}\text { Diltiazem ER } \\
\mathrm{n}=199\end{array}$ \\
\hline Age, Years & $58.2 \pm 11.8$ & $61.8 \pm 11.5$ & $57.3 \pm 11.0$ & $57.7 \pm 9.9$ & $67.0 \pm 12.6$ \\
\hline Height, $\mathrm{cm}$ & $168.1 \pm 10.2$ & $166.9 \pm 14.1$ & $168.8 \pm 15.4$ & $168.7 \pm 9.8$ & $168.3 \pm 10.5$ \\
\hline Weight, kg & $87.7 \pm 21.2$ & $81.9 \pm 18.5$ & $84.0 \pm 20.0$ & $87.5 \pm 19.9$ & $84.5 \pm 17.9$ \\
\hline Waist circumference, $\mathrm{cm}$ & $102.7 \pm 21.2$ & $94.4 \pm 14.0$ & $96.4 \pm 16.7$ & $101.1 \pm 15.4$ & $88.5 \pm 12.4$ \\
\hline $\mathrm{BMI}, \mathrm{kg} / \mathrm{m}^{2}$ & $31.3 \pm 6.8$ & $29.5 \pm 6.2$ & $29.8 \pm 6.8$ & $30.9 \pm 6.2$ & $29.7 \pm 5.5$ \\
\hline \multicolumn{6}{|l|}{ BMI Category, \% } \\
\hline$<27$ & 26.6 & 37.2 & 33.7 & 29.1 & 31.2 \\
\hline $27-30$ & 18.0 & 22.5 & 21.8 & 18.5 & 27.6 \\
\hline$>30$ & 46.1 & 38.0 & 36.8 & 45.8 & 39.7 \\
\hline Current smoker, \% & 11.2 & 12.1 & 10.6 & 12.0 & 12.6 \\
\hline Previous smoker, \% & 75.8 & 74.4 & 78.8 & 87.1 & 94.7 \\
\hline Duration in pack years & $151.5 \pm 643.8$ & $94.1 \pm 210.4$ & $128.2 \pm 342.7$ & $78.7 \pm 185.0$ & $78.3 \pm 196.5$ \\
\hline Male, $\%$ & 59.1 & 54.0 & 58.9 & 58.0 & 53.3 \\
\hline \multicolumn{6}{|l|}{ Race, \% } \\
\hline Caucasian & 55.3 & 51.1 & 44.9 & 47.4 & 74.9 \\
\hline Black & 4.6 & 7.6 & 6.1 & 10.6 & 2.5 \\
\hline Asian & 25.5 & 24.5 & 34.1 & 28.3 & 3.0 \\
\hline Hispanic & 1.2 & 1.7 & 1.1 & 1.4 & 0.0 \\
\hline Other & 6.0 & 8.0 & 5.0 & 5.4 & 1.5 \\
\hline Missing & 7.3 & 7.1 & 8.9 & 6.8 & 18.1 \\
\hline Disease duration, yrs & $4.9 \pm 5.6$ & $4.9 \pm 6.7$ & $4.7 \pm 6.4$ & $5.9 \pm 6.4$ & $9.5 \pm 9.6$ \\
\hline Vascular disorders, $\%$ & 53.9 & 54.7 & 1.5 & 1.2 & 3.1 \\
\hline Cardiac disorders, $\%$ & 5.7 & 9.7 & 4.3 & 4.2 & 12.3 \\
\hline $\mathrm{SBP}, \mathrm{mmHG}^{\ddagger}$ & & & $149.7 \pm 14.7$ & $153.3 \pm 16.5$ & $150.2 \pm 15.0$ \\
\hline $\mathrm{DBP}, \mathrm{mmHG}^{\ddagger}$ & & & $88.7 \pm 9.8$ & $89.4 \pm 11.1$ & $87.0 \pm 8.3$ \\
\hline Pulse, bpm $\ddagger$ & & & $76.2 \pm 9.6$ & $75.1 \pm 8.9$ & $77.0 \pm 11.2$ \\
\hline eGFR, $\mathrm{ml} / \mathrm{min}^{\ddagger}$ & & & $84.3 \pm 17.4$ & $82.4 \pm 16.5$ & $78.1 \pm 20.7$ \\
\hline Serum Potassium, $\mathrm{mmol} / \mathrm{L}^{\ddagger}$ & & & $4.7 \pm 5.4$ & $5.4 \pm 20.8$ & $4.3 \pm 0.4$ \\
\hline LDL-C, mmol/L§ & & $3.1 \pm 1.1$ & & & \\
\hline HDL-C, mmol/L§ & & $1.4 \pm 2.0$ & & & \\
\hline Non HDL-C, mmol/L§ & & $4.0 \pm 1.4$ & & & \\
\hline $\mathrm{TC}, \mathrm{mmol} / \mathrm{L}^{\S}$ & & $5.3 \pm 1.3$ & & & \\
\hline $\mathrm{TG}, \mathrm{mmol} / \mathrm{L}^{\S}$ & & $2.1 \pm 1.6$ & & & \\
\hline $\mathrm{A} 1 \mathrm{C}, \% \pi$ & $7.5 \pm 1.4$ & $6.8 \pm 1.5$ & & & \\
\hline ACR, $\mathrm{mg} / \mathrm{mmol} / \mathrm{L}$ & $16.0 \pm 44.8$ & $16.8 \pm 33.0$ & $16.9 \pm 43.4$ & $24.5 \pm 51.7$ & $3.7 \pm 9.8$ \\
\hline FPG, mmol/L & $8.4 \pm 2.9$ & $7.0 \pm 3.9$ & & & \\
\hline
\end{tabular}

Mean \pm standard deviation. Previous smoker, duration in pack years (number of cigarettes per day $\mathrm{x}$ number of years as a smoker). Note that patients may have taken more than one study drug and therefore maybe represented in more than one study drug group.

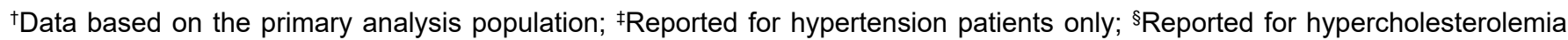
patients only; ${ }^{\top} \mathrm{A} 1 \mathrm{C}$ and FPG reported for hypercholesterolemia and type 2 diabetes patients only.

ditions in 2037 (76.8\%) of C patients, with most of the conditions classified as vascular disorders (54.7\%), followed by metabolic and nutritional disorders (49.2\%), cardiac disorders (9.7\%) and endocrine disorders (3.9\%) (Figure 2B). There were 6777 concomitant medications being taken in the $2146 \mathrm{C}$ patients (81\%), with LLT, AHAs and renin-angiotensin agents being the most common (Figure 3B). Colesevelam was given in sachet powder form in $60.1 \%$ of patients, with $37.3 \%$ given daily tablets. Most patients taking tablets were prescribed 6 


\section{A, Metformin Extended-Release, $\mathrm{N}=1690$}

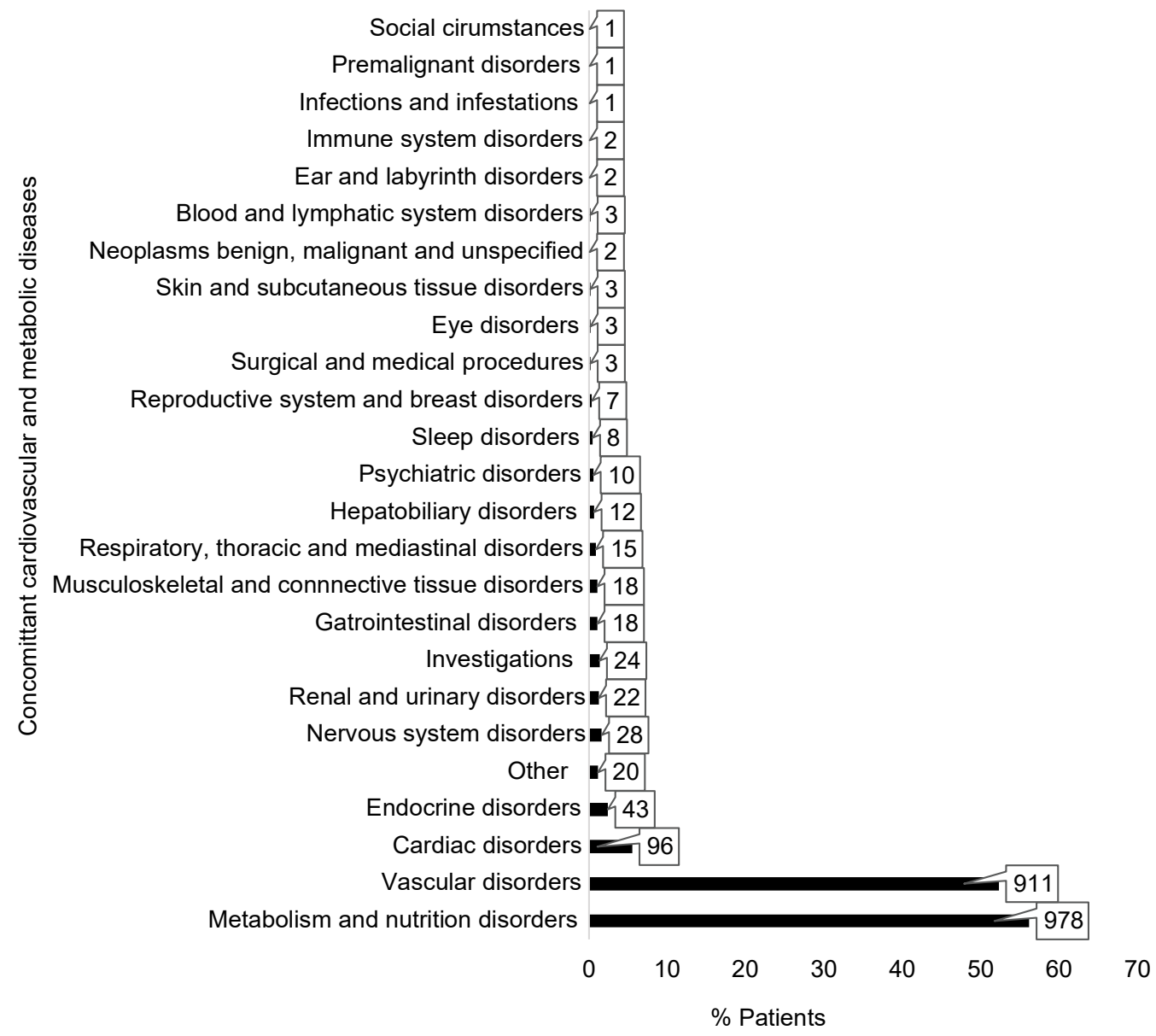

\section{B, Colesevelam, $\mathrm{N}=2651$}

\section{$\%$ Patients}

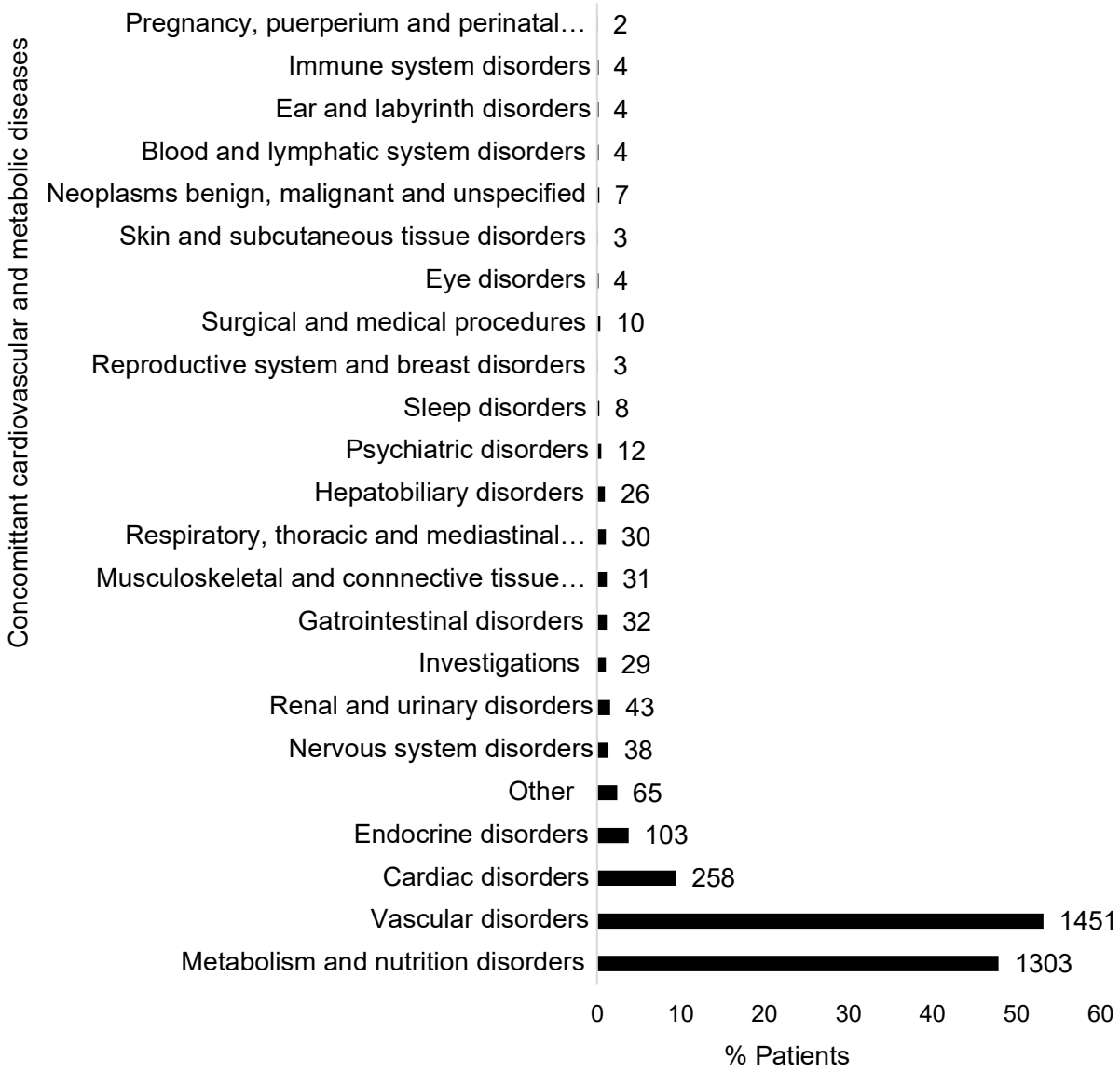


C, Azilsartan, $\mathrm{N}=1929$

\begin{tabular}{l|l} 
Pancreatic disorders & 1
\end{tabular}

General disorders and adminitsration site conditions । 3 Infections and infestations 1

Ear and labyrinth disorders 2 Neoplasms benign, malignant and unspecified 1

Skin and subcutaneous tissue disorders I 5

Eye disorders । 3

Surgical and medical procedures 2

Reproductive system and breast disorders । 3

Sleep disorders I 6

Psychiatric disorders I 12

Hepatobiliary disorders 19

Respiratory, thoracic and mediastinal disorders a 19

Musculoskeletal and connnective tissue disorders I 12

Gatrointestinal disorders 18

Investigations 13

Renal and urinary disorders 20

Nervous system disorders 17

Other 16

Endocrine disorders 52

Cardiac disorders 82

Vascular disorders $\boldsymbol{a} 28$

Metabolism and nutrition disorders

$\begin{array}{lllllllllll}0 & 5 & 10 & 15 & 20 & 25 & 30 & 35 & 40 & 45 & 50\end{array}$

$\%$ Patients

D, Azilsartan/Chlorthalidone, $\mathrm{N}=1012$

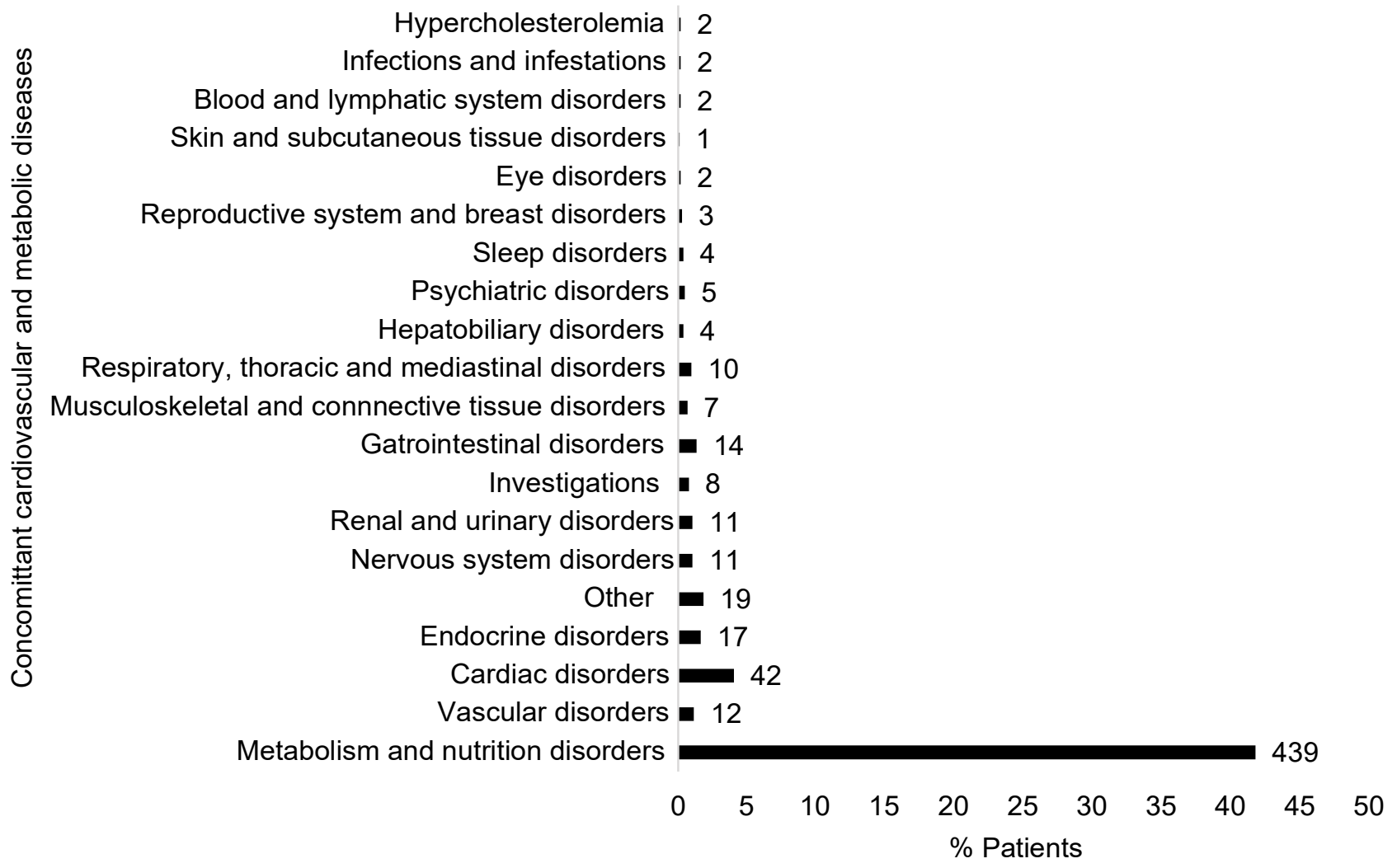


DOI: 10.23937/2474-3690/1510053

ISSN: 2474-3690

E, Diltiazem Extended-Release, $\mathrm{N}=228$

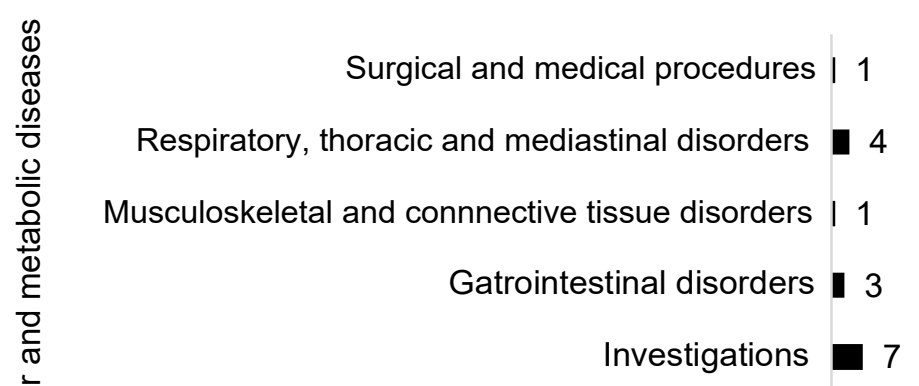

Renal and urinary disorders I 2

Nervous system disorders 4

Other 4

Endocrine disorders 3

Cardiac disorders

Vascular disorders $\square$

Metabolism and nutrition disorders
28 


\section{B, Colesevelam, N=2651}

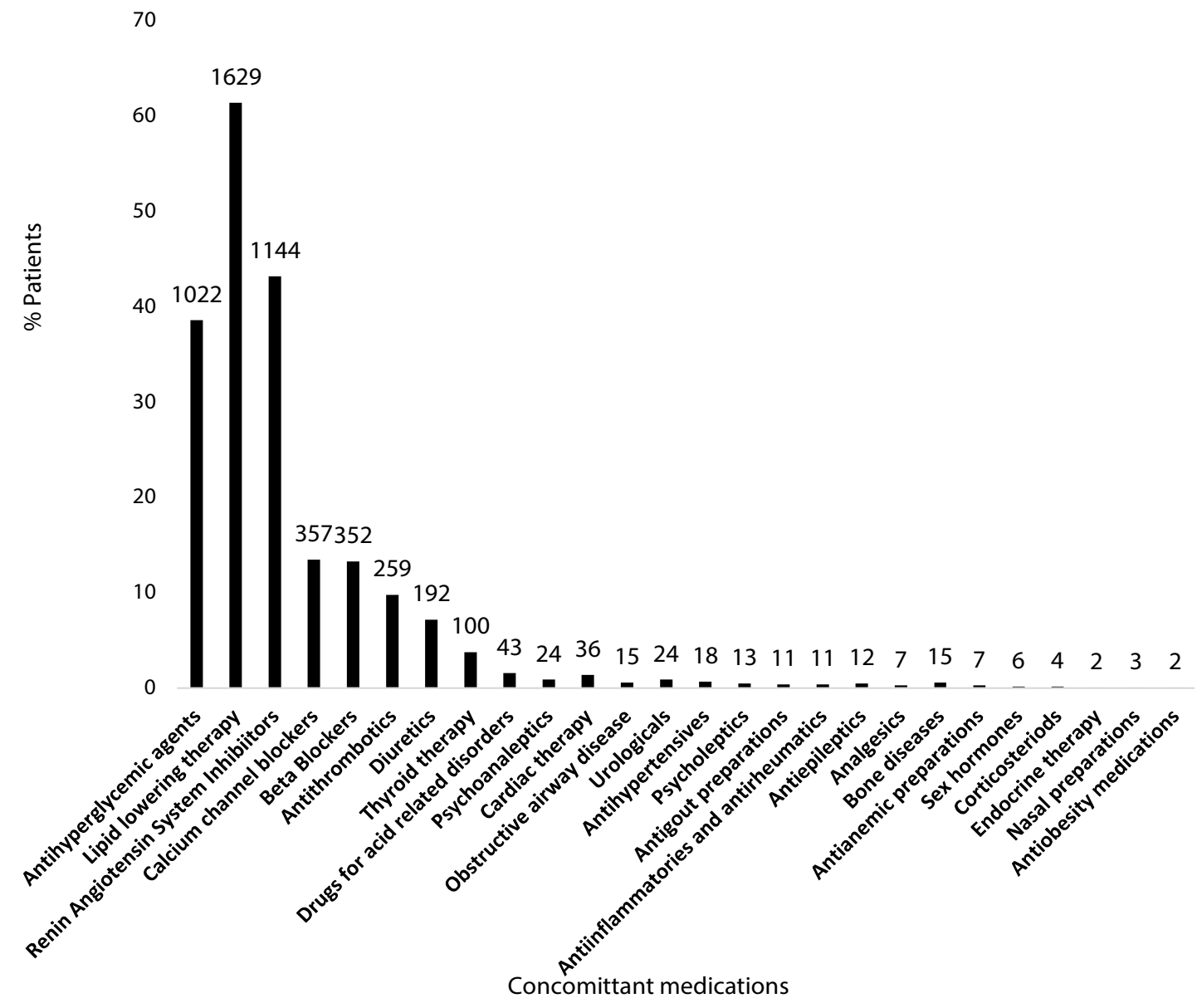

C, Azilsartan, $\mathrm{N}=1929$

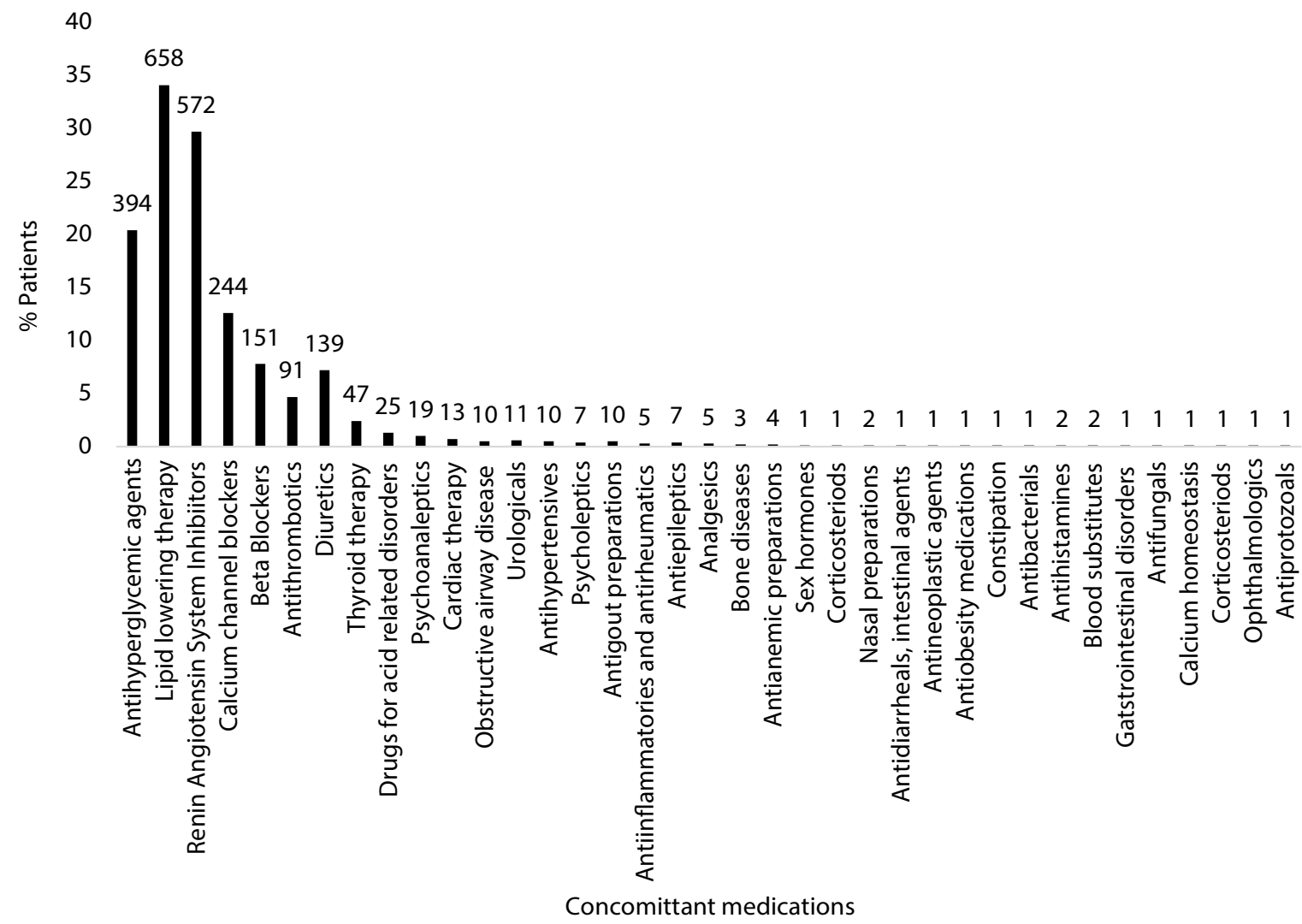


D, Azilsartan/Chlorthalidone, $\mathrm{N}=1012$

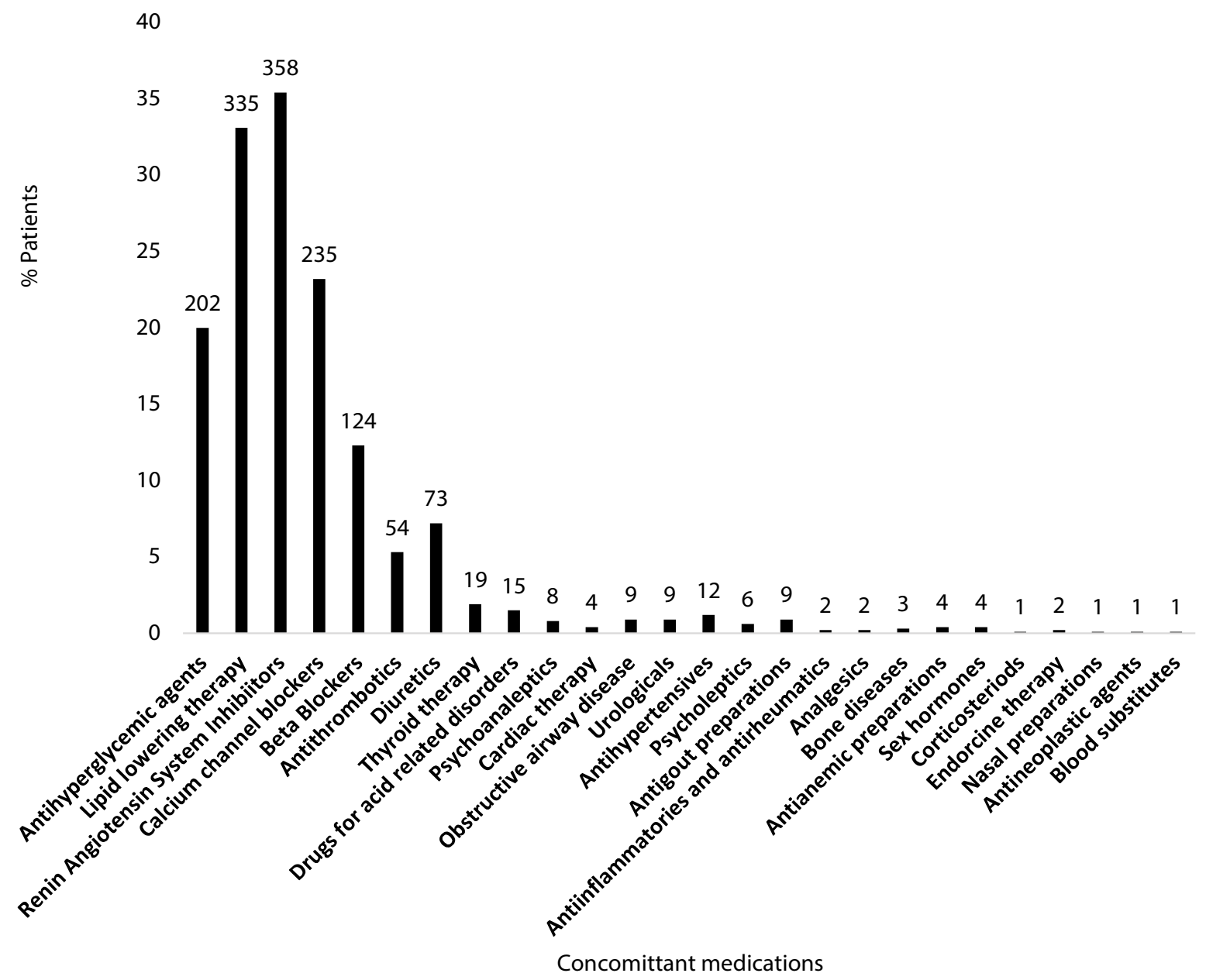


E, Diltiazem Extended-Release, $\mathrm{N}=228$

60

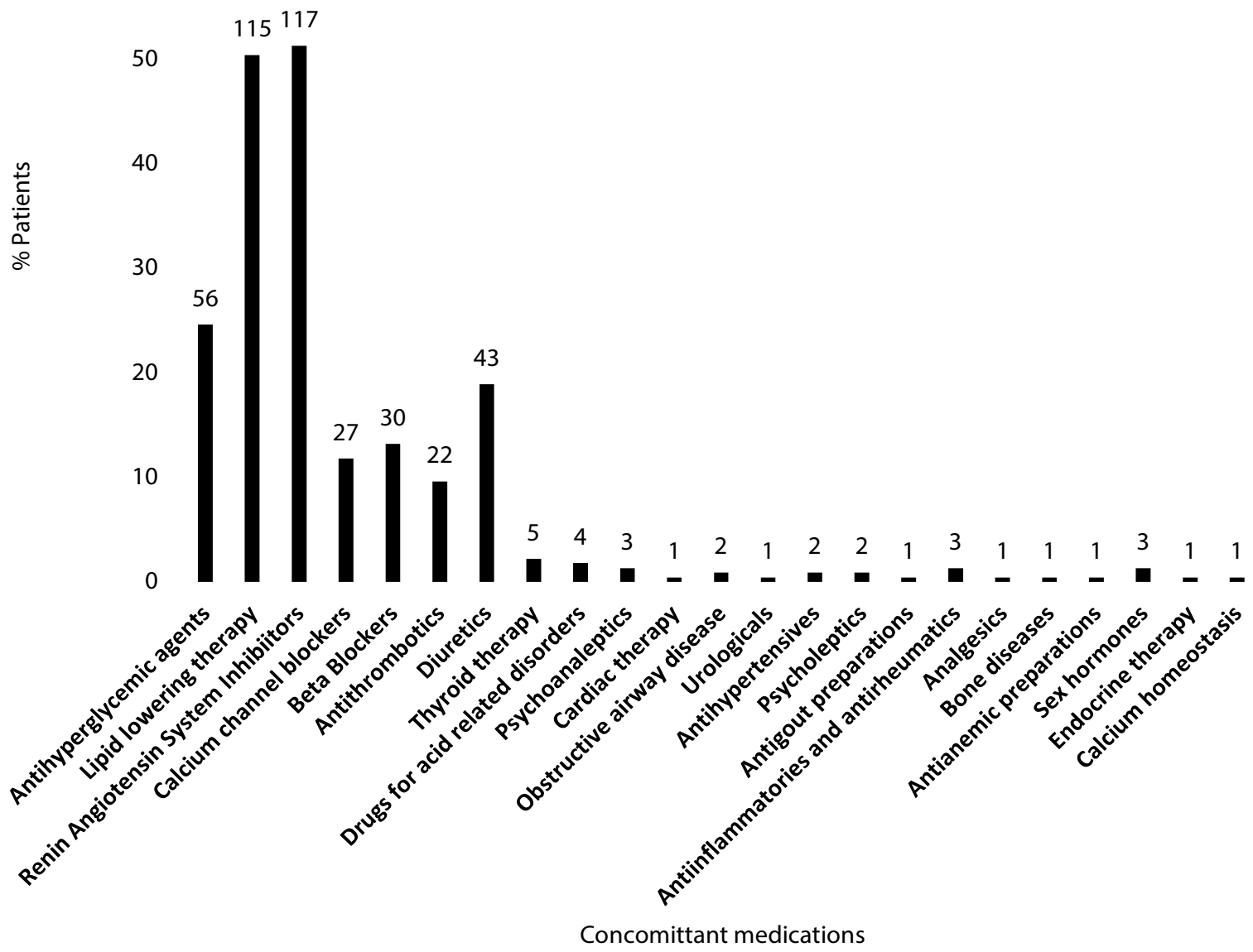

Figure 3: Concomitant medications by study drug. A) Metformin Extended-Release; B) Colesevelam; C) Azilsartan; D) Azilsartan/Chlorthalidone; E) Diltiazem Extended-Release.

Note: Concomitant medications are reported at ATC level 2 , using the safety population.

tablets per day (Figure 4B). Patients were given $\mathrm{C}$ as monotherapy $(41.5 \%)$ or add-on therapy $(57.1 \%)$. The major reason for monotherapy was statin intolerance or contraindication (49.1\%); while the major reason for add-on therapy was patients not at target with full dose statin (47.2\%) (Figure 5B).

\section{Hypertension}

The diagnosis for initiating treatment with AZI, AZI/ CHL or TXC was primarily HTN (96.8\%, 96.4\%, 87.9\% respectively). There were 1982 concomitant conditions in 993 (51.5\%) of the AZI patients; 986 concomitant conditions in 494 (48.8\%) of the AZI/CHL patients; and 305 concomitant conditions in 179 (78.5\%) of the TXC patients. Most conditions were classified as metabolic and nutritional disorders (53.1\%), followed by cardiac disorders (6.9\%) (Figure 2C, Figure 2D and Figure 2E). There were 2880 concomitant medications being taken in 1260 (65.3\%) of the AZI patients; 1768 in 672 (66.4\%) of the AZI/CHL patients; and 524 in 196 (86\%) of the TXC patients (Figure 3C, Figure 3D and Figure 3E). LLT, AHAs and renin-angiotensin agents were the most common concomitant medications (Figure 3C, Figure 3D and Fig- ure $3 \mathrm{E}$ ). The most common total daily dosing was 40 $\mathrm{mg}, 40 / 12.5 \mathrm{mg}$ and $240 \mathrm{mg}$ for AZI, AZI/CHL and TXC respectively (Figure 4C, Figure 4D and Figure 4E). For all hypertension drugs, treatment was generally initiated as a switch from prior treatment $(\mathrm{AZI}=49.8 \%$; $\mathrm{AZI} / \mathrm{CHL}$ $=65.5 \%$; $\mathrm{TXC}=43.2 \%)$, versus initial treatment $(\mathrm{AZI}=$ 34.5\%; $\mathrm{AZI} / \mathrm{CHL}=19.7$; TXC $=19.6 \%$ ) or add-on to a current therapy $(\mathrm{AZI}=14.1 \%$; $\mathrm{AZI} / \mathrm{CHL}=12.9 \%$; $\mathrm{TXC} 37.2 \%)$. The most common medications that patients were switched from were angiotensin-converting enzyme (ACE) inhibitors ( $A Z I=49.8 \%$; followed by ARBs 33.3\%, diuretics $10.5 \%$, CCBs $9.4 \%$, beta blockers $7.2 \%$ and alpha blockers 2.5\%), ARBs ( $\mathrm{ZZI} / \mathrm{CHL}=43.9 \%$, followed by ACE inhibitors $42 \%$, diuretics $35 \%$, CCBs $13.8 \%$, beta blockers $4.3 \%$ and alpha blockers $2.1 \%$ ) or CCBs (TXC = $67.4 \%$, followed by beta blockers $14 \%$, ACE inhibitors $9.3 \%$, diuretics $8.1 \%$ and $A R B s 1.2 \%)$. The major reason for switching was lack of efficacy (AZI $=60.1 \%$; AZI $/ \mathrm{CHL}$ $=71.8 \%$; TXC $=41.9 \%$ (Figure $5 \mathrm{C}$ ).

\section{Discussion}

The CV-CARE patients represent a population with significant risk factor burden, with a high number of 
A, Metformin Extended-Release

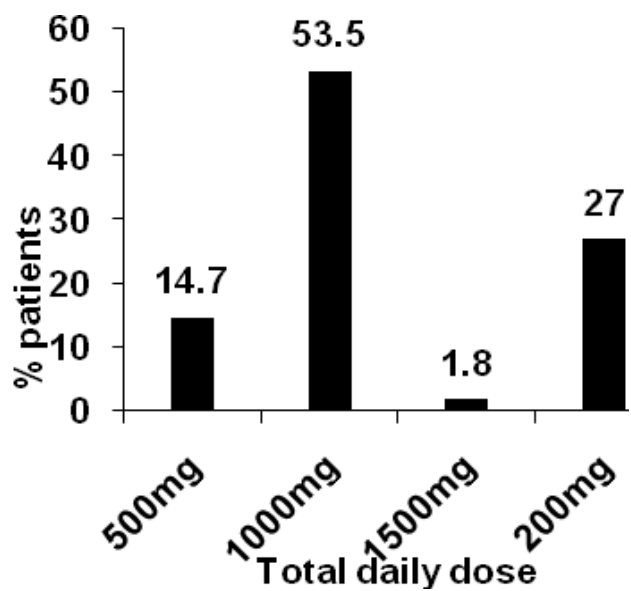

C, Azilsartan

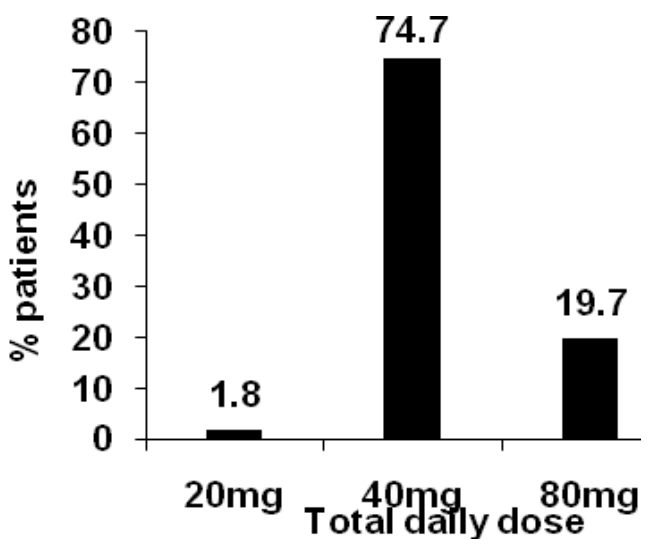

E, Diltiazem Extended-Release
B, Colesevelam

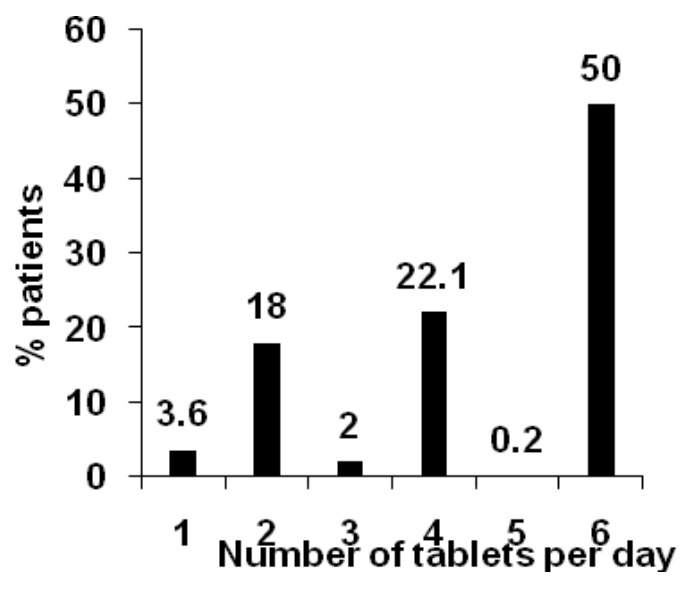

D, Azilsartan/Chlorthalidone

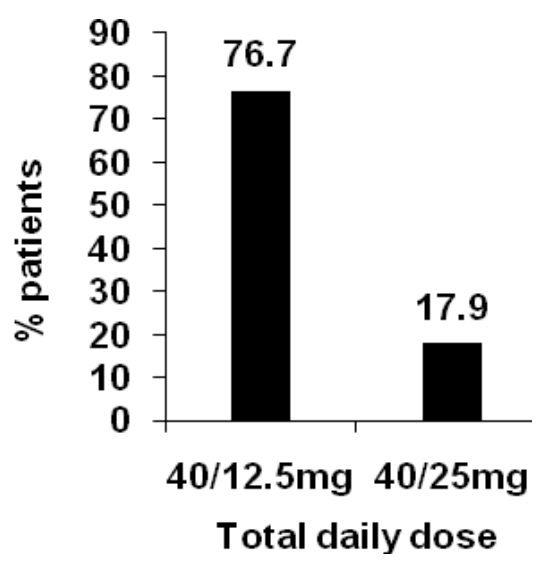

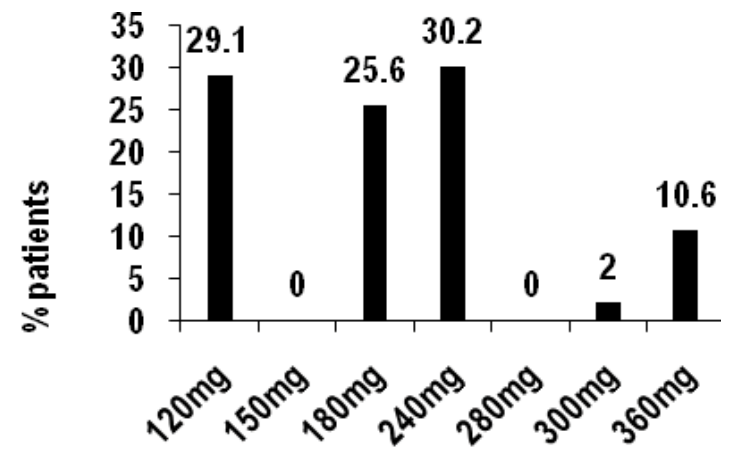

Total daily dose

Figure 4: Treatment by study drug in primary analysis population. A) Metformin extended-release; B) Colesevelam; C) Azilsartan; D) Azilsartan/Chlorthalidone; E) Diltiazem extended-release.

concomitant diseases and medications. The presence of T2DM, HCh, and HTN significantly increases the risk of cardiovascular disease and mortality [37]. Indeed, the percentage of patients with established vascular disorders was high in the T2DM (53.9\%) and $\mathrm{HCh}$ (54.7\%) patients. However, the percentage of cardiac disorders reported was low at 5.7\% (T2DM), 9.7\% ( $\mathrm{HCh}$ ) and $4.7 \%$ (HTN). This could be explained by the fact that the CV-CARE registry was mainly a primary care registry and patient selection may have favored patients at the primary care stage rather than secondary prevention stage.

\section{Type 2 diabetes mellitus}

Patients reporting T2DM had a disease duration of approximately 5 years, with an A1C at $7.5 \%$. Most patients reported metformin IR use as initial treatment, before switching to MetER. Most patients switched to 


\section{A, Metformin Extended-Release}

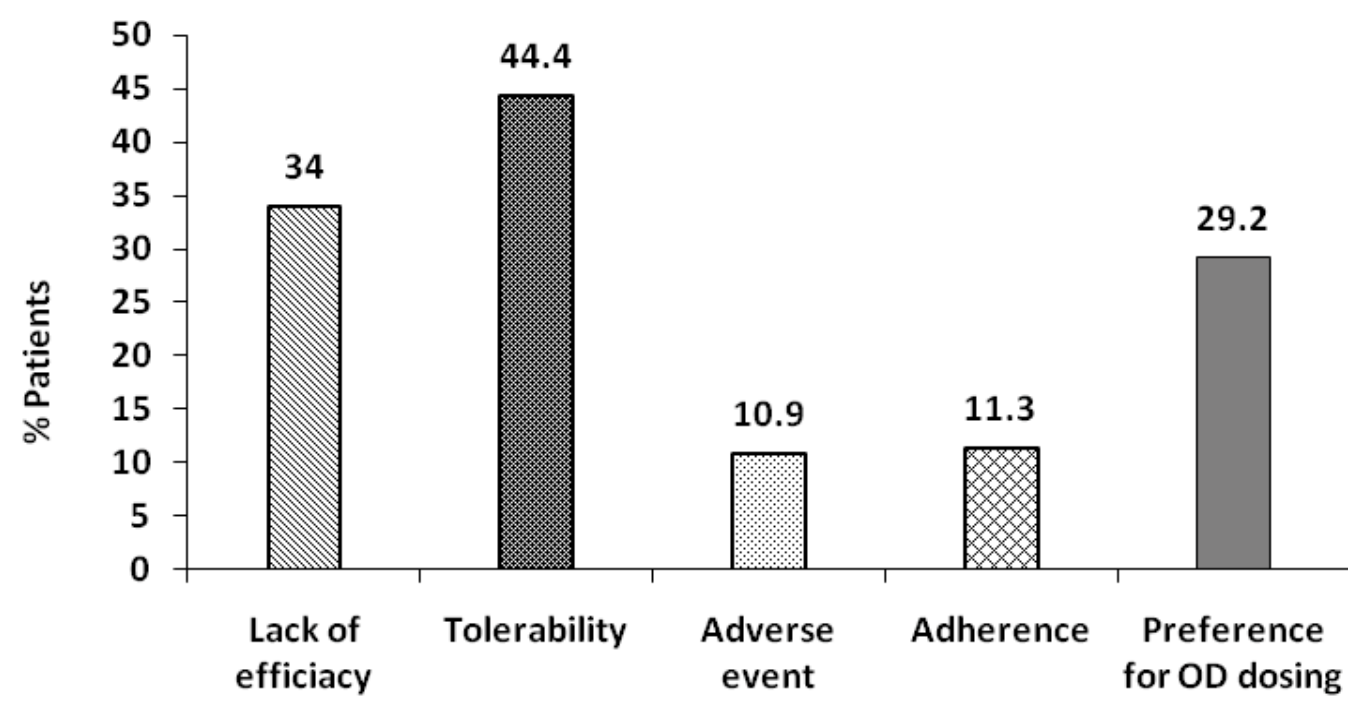

Rationale for initiating treatment

\section{B, Colesevelam}

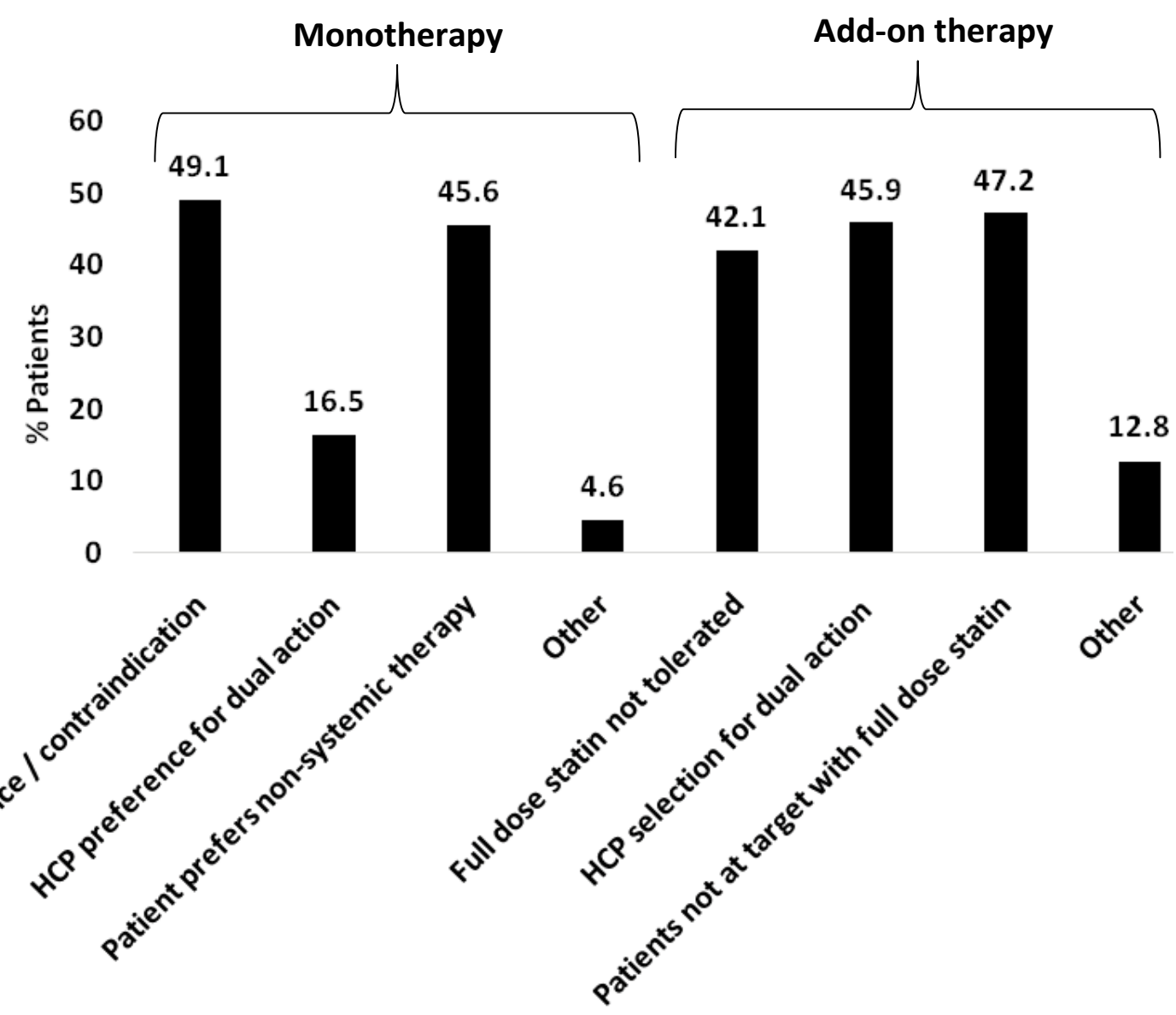

Rationale for initiating treatment 


\section{C, Azilsartan, Azilsartan/Chlorthalidone, Diltiazem Extended-Release}

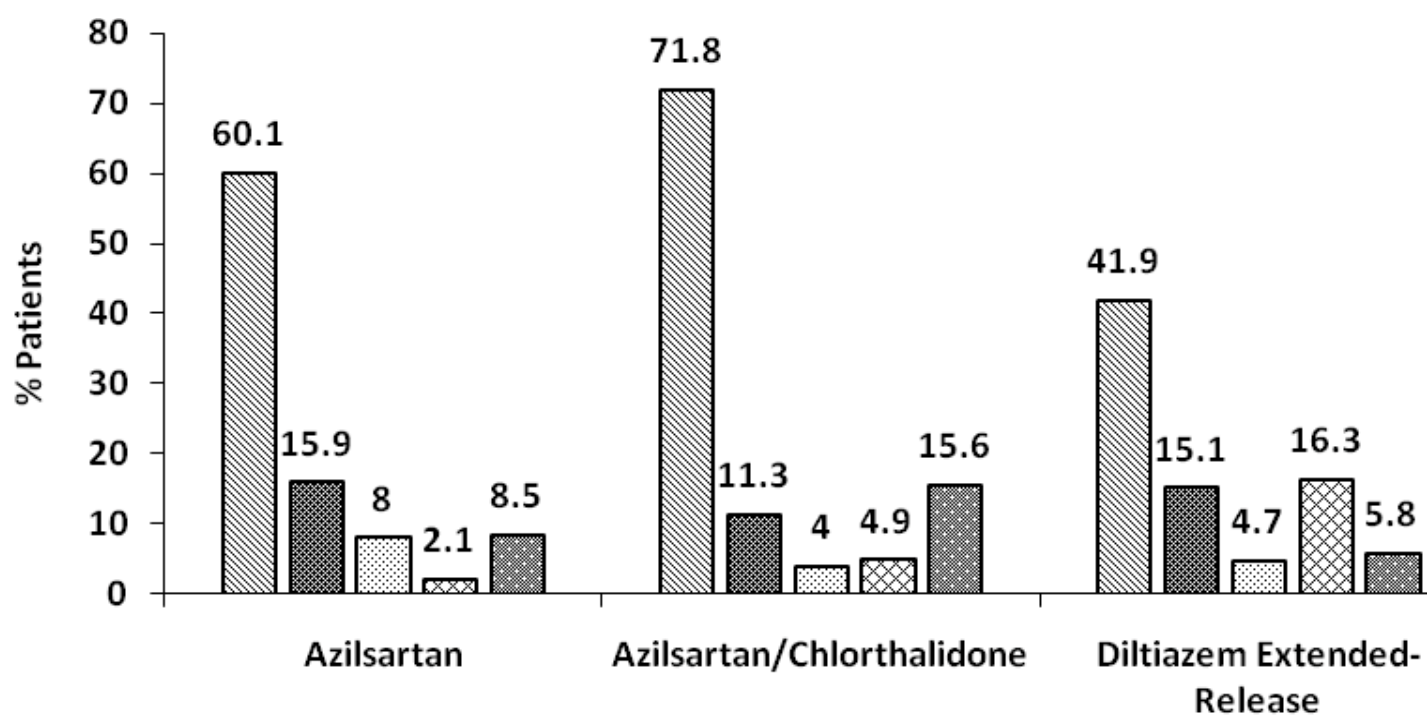

Rationale for initiating treatment

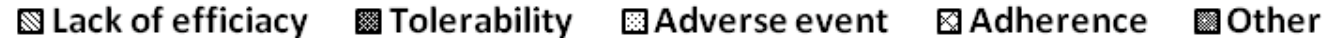

Figure 5: Rationale for initiating. A) Metformin extended-release; B) Colesevelam; C) Azilsartan, Azilsartan/Chlorthalidone, or Diltiazem extended-release.

MetER due to the inability to tolerate metformin IR. The GI side effects of metformin IR have been previously reported in up to $25 \%$ of patients [7]. The most common total daily dose was $1000 \mathrm{mg}$, which is the recommended starting dose. Maximum daily dose is $2000 \mathrm{mg}$, which $27 \%$ of the CV-CARE population reported.

\section{Hypercholesterolemia}

The Canadian screening guidelines for hypercholesterolemia suggest pharmacological intervention to achieve an $L D L-C \leq 2.0 \mathrm{mmol} / \mathrm{L}$, with additional reductions to $<1.4 \mathrm{mmol} / \mathrm{L}$ and even $<1 \mathrm{mmol} / \mathrm{L}$ being associated with further cardiovascular risk reduction $[17,18]$. The CV-CARE population reported, on average, a LDL-C of $3.1 \mathrm{mmol} / \mathrm{L}$, a HDL-C of $1.4 \mathrm{mmol} / \mathrm{L}$ and a non-HDL-C at $4 \mathrm{mmol} / \mathrm{L}$. Based on the age, blood pressure and diabetes status of this population, most were not at target and required treatment intensification. The Canadian Cardiovascular Society recommends statin up titration or add-on therapy with ezetimibe and/or bile acid sequestrants [14]. In line with this recommendation, approximately half of the CV-CARE population were given $\mathrm{C}$ as an add-on therapy (57.1\%), although there was still $41.5 \%$ on $C$ as monotherapy (41.5\%). Colesevelam monotherapy has been shown to reduce mean serum LDL-C levels by $9-19 \%$ [3]. However, when used in combination with an HMG-CoA reductase inhibitor (statin), $C$ induces additive reductions in LDL-C that are $10-16 \%$ greater than those achieved by monotherapy with a statin [38]. As such, C provides a useful addition to primary therapy with statins in the treatment of hypercholesterolemia. Despite the evidence of the relationship between lower LDL-C and reduced cardiovascular disease risk [39], many patients received treatment that consisted predominantly of statin monotherapy. A large percentage of the registry population reported statin intolerance or contraindication $(49.1 \%)$ as the reason for using $C$, in line with the reported poor tolerability of statins in the literature [40]. A large proportion of the CV-CARE population reported taking $C$ in sachet powder form, supporting the patient preference of a drink (for ease of swallowing) versus tablets $[41,42]$.

\section{Hypertension}

At enrollment, patients had an average disease duration of 5.5 years at a mean age of 59.6 years. This is not an unexpected finding given that prevalence of hypertension in Canada has been reported to increase significantly from ages 49-84 years [23]. According to Hypertension Canada 2018 guidelines [43], this cohort would be classified as a moderate to high risk population (due to cardiovascular risk factors). In this category, blood pressure threshold for initiation of antihypertensive therapy, in those without diabetes, is $\geq 140 \mathrm{mmHg} / \geq 90$ $\mathrm{mmHg}$, with long-acting diuretics preferred over shorter acting diuretics, ACE-I, ARBs, long-acting CCB, beta blockers (not first line for those $>60$ years) and single pill combinations being recommended [43]. We can see that in the CV-CARE population, multiple first line medications were being used to manage disease, often in 
combination, which has been shown to minimize counter-regulatory mechanisms that act to restore blood pressure values to pre-treatment levels $[44,45]$. Most patients require more than one medication to control their hypertension [46]. These anti-hypertensives were most often prescribed for lack of prior treatment efficacy. The most common dose of AZI was $40 \mathrm{mg}$ and the $\mathrm{AZI} / \mathrm{CHL}$ recommend starting dose of $40 / 12.5 \mathrm{mg}$ is also the most common reported in the CV-CARE population. The most common total daily dosing of TXC was $240 \mathrm{mg}$ despite blood pressure recordings being above target. As the anti-hypertensive effect of TXC is dose related, and higher doses of $280 \mathrm{mg}, 300 \mathrm{mg}$ and 360 mg were available, there may have been an opportunity for a greater number of patients to achieve target blood pressure if the dosage had been increased [47]. It has been previously reported that physicians can fail to adequately titrate doses of anti-hypertensives [47].

\section{Study limitations}

There are several limitations to this study. As this data comes from a registry there are potential biases from treatment selection (health care professional, patient and registry inclusion criteria), reporting bias (health care professional), and participation bias (patients). The registry was observational and as such patients were not randomized between the treatment groups and time between study entry and follow-up visits varies between participants. As this was taking place during routine clinical care, not all parameters were collected for all patients, leading to missing data. The analysis is retrospective and descriptive in nature only. Finally, this registry is Canada-based and specific to BHC CV/MET portfolio, and as such, data should not be extrapolated.

\section{Acknowledgments}

MB (Maxime) and JB conceived the study in collaboration with Drs. Bell, Goldenberg and Cheng. Dr. Cheng was also involved in patient recruitment and follow up. JSS Medical Research was hired to run the study, prepare the data and perform all statistical analyses. EP oversaw individual clinical site monitoring as part of the study's Clinical Trial Associate team. MB and JB interpreted the results. $M B$ reviewed the literature and wrote the manuscript with the assistance of JB and EP. MB, JB, EP, $R G, W C, N F A$, and $A B$ critically revised the manuscript for scientific quality and content. All authors approved the final version for publication.

\section{Funding}

This study was sponsored in full by Bausch Health (formerly Valeant Pharmaceuticals LLP), Canada.

\section{Disclosures}

RG reports research support from Abbott, AstraZeneca, Boehringer Ingelheim, Eli Lilly, GlaxoSmithKline, Janssen, Medtronic, Merck, Novartis, Novo Nordisk, Roche, Sanofi, and Takeda; serving on advisory panels for AstraZeneca, Boehringer Ingelheim, Eli Lilly, Janssen, Merck, Novo Nordisk, Roche, Sanofi, and Takeda; speaker bureaus for Abbott, AstraZeneca, Boehringer Ingelheim, Eli Lilly, Janssen, Merck, Novo Nordisk, Sanofi, and Servier; consulting for AstraZeneca, Bausch Health, Boehringer Ingelheim, Eli Lilly, Janssen, Novo Nordisk, and Takeda. AB has received research support, consulting fees and/or speaker honorarium from the following commercial organizations: Amgen, Bristol Myers Squibb, Janssen, AstraZeneca, Pfizer, Bayer, Lilly, Boehringer Ingelheim, Canopy Growth, Sanofi, Bausch Health. WC has no conflicts of interest to declare. MB (Melonie Burrows), EP and NFA are employees of Bausch Health Companies. JB and MB (Maxime Barakat) are employees of, and shareholders in, Bausch Health Companies.

\section{References}

1. Leiter LA, David H Fitchett, Richard E Gilbert, Milan Gupta, G B John Mancini, et al. (2011) Cardiometabolic risk in Canada: A detailed analysis and position paper by the Cardiometabolic risk working group. Can J Cardiol 27: e1-e33.

2. Srivastava AK (2012) Challenges in the treatment of cardiometabolic syndrome. Indian J Pharmacol 44: 155-156.

3. (2011) Public health agency of canada, diabetes in canada: Facts and figures from a public health perspective. Ottawa, Canada.

4. Stratton IM, Adler AI, Neil HAW, DR Matthews, SE Manley, et al. (2000) Association of glycaemia with macrovascular and microvascular complications of type 2 diabetes (UKPDS 35P observational study. BMJ 321: 405-412.

5. Leiter LA, Berard L, Bowering CK, Alice Y Cheng, Keith G Dawson, et al. (2013) Type 2 diabetes mellitus management in canada: Is it improving? Can J Diabetes 37: 82-89.

6. Donnelly LA, Morris AD, Pearson ER (2009) Adherence in patients transferred from immediate release metformin to a sustained release formulation: A population-based study. Diabetes Obes Metab 11: 338-342.

7. Blonde L, Dailey GE, Jabbour SA, Charles A Reasner, Donna J Millse (2004) Gastrointestinal tolerability of extended-release metformin tablets compared to immediate-release metformin tablets: Results of a retrospective cohort study. Curr Med Res Opi 20: 565-572.

8. Schwartz S, Fonseca V, Berner B, Marilou Cramer, Yu-Kun Chiang, et al. (2006) Efficacy, tolerability, and safety of a novel once-daily ER metformin in patients with type 2 diabetes. Diabetes Care 29: 759-764.

9. (2012) Metformin hydrochloride, extended release product monograph. Valeant Canada.

10. Baigent C, Keech A, Kearney PM, G Buck, C Pollicino, et al. (2005) Efficacy and safety of cholesterol-lowering treatment: prospective meta-analysis of data from 90,056 participants in 14 randomized trials of statins. Lancet 366 : 1267-1278.

11. Jones PH (2004) Lower is better: LDL-C goal achievement and statin efficacy in coronary prevention. Medscape Cardiology.

12. Yusuf S, Hawken S, Ounpuu S (2004) INTERHEART study investigators. Effect of potentially modifiable risk factors associated with myocardial infarction in 52 countries (the INTERHEART study): Case-control study. Lancet 364: 937-952. 
13. CTT Collaboration, Baigent C, Blackwell L, Emberson J, LE Holland, et al. (2010) Efficacy and safety of more intensive lowering of LDL cholesterol: A meta-analysis of data from 170,000 participants in 26 randomized trials. Lancet 13: 1670-1681.

14. Anderson TJ, Gregoire J, Pearson GJ, Arden R Barry, Patrick Couture, et al. (2016) Canadian cardiovascular society guidelines for the management of dyslipidemia for the prevention of cardiovascular disease in the adult. Can $\mathrm{J}$ Cardiol 32: 1263-1282.

15. Cannon CP, Braunwald E, McCabe CH (2004) Pravastatin or atorvastatin evaluation and infection therapy-thrombolysis in myocardial infarction 22 investigators. Intensive versus moderate lipid lowering with statins after acute coronary syndromes. New England Journal Medicine 350: 1495-1504.

16. Wiviott SD, de Lemos JA, Cannon CP, Michael Blazing, Sabina A Murphy, et al. (2006) A tale of two trials: A comparison of the post-acute coronary syndrome lipid-lowering trials A to $Z$ and PROVE IT-TIMI 22. Circulation 113: 14061414.

17. Cannon CP, Blazing MA, Giugliano RP, Amy McCagg, Jennifer A White, et al. (2015) Ezetimibe Added to Statin Therapy after Acute Coronary Syndromes. N Engl J Med 372: 2387-2397.

18. Giugliano RP, Pedersen TP, Park JG, Gaetano M De Ferrari, Zbigniew A Gaciong, et al. (2017) Clinical efficacy and safety of achieving very low LDL-cholesterol concentrations with the PCSK9 inhibitor evolocumab: A prespecified secondary analysis of the FOURIER trial. Lancet 390: 19621971.

19. Mach F, Baigent C, Alberico L, Konstantinos C Koskinas, Manuela Casula, et al. (2019) ESC/EAS Guidelines for the management of dyslipidaemias: Lipid modification to reduce cardiovascular risk. Eur Heart $\mathrm{J}$.

20. Arnett DK, Blumenthal RS, Albert MA, Andrew B Buroker, Zachary D Goldberger, et al. (2019) ACC/AHA Guideline on the primary prevention of cardiovascular disease. Journal of American College of Cardiology 74: 177-232.

21. (2014) Colesevelam hydrochloride product monograph. Valeant, Canada.

22. Lim SS, Vos T, Flaxman AD, Goodarz Danaei, Kenji Shibuya, et al. (2012) A comparative risk assessment of burden of disease and injury attributable to 67 risk factors and risk factor clusters in 21 regions, 1990-2010: A systematic analysis for the global burden of disease study 2010 . The Lancet 380: 2224-2260.

23. Robitaille C, Dai S, Waters C, Lidia Loukine, Christina Bancej, et al. (2012) Diagnosed hypertension in Canada: Incidence, prevalence and associated mortality. CMAJ 184: 49-56.

24. Wilkins K, Campbell NR, Joffres MR, Finlay A McAlister, Marianne Nichol, et al. (2010) Blood pressure in canadian adults. Health Rep.

25. (2015) Azilsartan medoxomil product monograph. Valeant, Canada.

26. Bakris GL, Sica D, Weber M, William B White, Andrew Roberts, et al. (2011) The comparative effects of azilsartan medoxomil and olmesartan on ambulatory and clinic blood pressure. J Clin Hypertens (Greenwich) 13: 81-88.

27. White WB, Weber MA, Sica D, George L Bakris, Alfonso Perez, et al. (2011) Effects of the angiotensin receptor blocker azilsartan medoxomil versus olmesartan and valsartan on ambulatory and clinical blood pressure in patients with stages 1 and 2 hypertension. Hypertension 57: 413-420.

28. Cushman, WC, Bakris GL, White WB, Michael A Weber, Domenic Sica, et al. (2012) Azilsartan medoxomil plus chlorthalidone reduces blood pressure more effectively than olmesartan plus hydrochlorothiaizde in Stage 2 Systolic Hypertension. Hypertension 60: 310-318.

29. Sica D, Bakris GL, White WB, Michael A Weber, William C Cushman, et al. (2012) Blood pressure-lowering efficacy of the fixed-dose combination of azilsartan medoxomil and chlorthalidone: A factorial study. J Clin Hypertens (Greenwich) 14: 284-292.

30. (2017) Diltiazem hydrochloride, extended-release product monograph. Valeant, Canada.

31. White WB, Lacourciere Y, Gana T, Maria G Pascual, David H Smith, et al. (2004) Effects of graded-release diltiazem versus ramipril, dosed at bedtime, on early morning blood pressure, heart rate, and the rate-pressure product. Am Heart J 148: 628-634.

32. Papp KA, Gooderham M, Beecker J, Charles W Lynde, Isabelle Delorme, et al. (2019) Rationale, objectives and design of PURE, a prospective registry of patients with moderate to severe chronic plaque psoriasis in Canada and Latin America. BMC Dermatol 19: 2-7.

33. Houle SKD, Padwal R, Tsuyuki RT (2013) The 2012-2013 canadian hypertension education program (CHEP) guidelines for pharmacists: An update. Can Pharm J (Ott) 146: $146-150$

34. (2013) Canadian diabetes association clinical practice guidelines expert committee. Canadian diabetes association 2013 clinical practice guidelines for the prevention and management of diabetes in canada. Can J Diabetes 37.

35. Anderson TJ, Gregoire J, Hegele RA, Patrick Couture, GB John Mancini, et al. (2013) 2012 update of the Canadian Cardiovascular Society guidelines for the diagnosis and treatment of dyslipidemia for the prevention of cardiovascular disease in the adult. Can J Cardiol 29: 151-167.

36. Daskalopoulou SS, Rabi DM, Zarnke KB, Kaberi Dasgupta, Kara Nerenberg, et al. (2015) The 2015 Canadian Hypertension Education Program recommendations for blood pressure measurement, diagnosis, assessment of risk, prevention and treatment of hypertension. Can $\mathrm{J}$ Cardiol 31: 549-568.

37. Kaur J (2014) A comprehensive review on metabolic syndrome. Cardiol Res Pract.

38. Robinson DM, Keating GM (2007) Colesevelam. American Journal Cardiovascular Drugs 7: 453-465.

39. Austin MA, Hutter CM, Zimmern RL, Steve E Humphries (2004) Familial Hypercholesterolemia and Coronary Heart Disease: A huge association review. Am J Epidemiol 160: 421-429.

40. Koren MJ, Lundqvist $P$, Bolognese $M$, Joel M Neutel, Maria Laura Monsalvo, et al. (2014) Anti-PCSK9 Monotherapy for Hypercholesterolemia: The MENDEL-2 Randomized, Controlled Phase III Clinical Trial of Evolocumab. J Am Coll Cardiol 63: 2531-2540.

41. Strachan I, Greener M (2005) Medication-related swallowing difficulties may be more common than we realize. Pharmacology Practice 15: 411-414.

42. Liu F, Ranmal S, Batchelor HK, Mine Orlu-Gul, Terry B Ernest, et al. (2014) Patient-centered pharmaceutical design to improve acceptability of medicines: Similarities and dif- 
ferences in paediatric and geriatric populations. Drugs 74 : 1871-1889.

43. Hypertension Canada (2018) Hypertension highlights. A practical guide informed by the hypertension Canada guidelines for diagnosis, risk assessment, prevention and treatment of hypertension.

44. Chen JM, Heran BS, Wright JM (2009) Blood pressure lowering efficacy of diuretics as second-line therapy for primary hypertension. Cochrane Database Syst Rev.

45. James PA, Oparil S, Carter BL, William C Cushman, Cheryl Dennison-Himmelfarb, et al. (2014) Evidence-based guideline for the management of high blood pressure in adults:
Report from the panel meetings appointed to the $8^{\text {th }}$ joint national committee. JAMA 311: 507-520.

46. Go AS, Bauman MA, Coleman SM, Gregg C Fonarow, Willie Lawrence, et al. (2014) An effective approach to high blood pressure control: A science advisory from the American Heart Association, the american college of cardiology and the centres for disease control and prevention. Hypertension 63: 878-885.

47. Okonofua EC, Simpson KN, Jesri A, Shakaib U Rehman, Valerie L Durkalski, et al. (2006) Therapeutic inertia is an impediment to achieving the Healthy People 2010 blood pressure control goals. Hypertension 47: 345-351. 